\title{
Dialect and the Learning of English as a Second Language in Kenya
}

\author{
Margaret Gatavi Njeru ${ }^{1}$ \\ ${ }^{1}$ Kenya \\ Correspondence: Margaret Gatavi Njeru, Kenya. E-mail: gatavimargaret@yahoo.com
}

Received: April 12, 2013

Accepted: May 23, 2013

Online Published: May 28, 2013

doi:10.5430/elr.v2n1p128

URL: http://dx.doi.org/10.5430/elr.v2n1p128

\begin{abstract}
The paper is not based on any empirical study that the researcher has carried out but on theoretical work. Kenya is a country composed of 42 different tribes, speaking different languages and each tribe has challenges in as far as acquiring/ learning English as a second language is concerned. The paper is meant to arouse interest in those who wish to do an empirical study as it gives an insight into the situation of English as a second language in Kenya.
\end{abstract}

Keywords: Dialect, English, a second language, Kenya

\begin{tabular}{|c|c|c|}
\hline $\mathrm{AOA}$ & - & Age of acquisition \\
\hline D1 & - & First dialect \\
\hline D2 & - & Second dialect \\
\hline L1 & - & First language \\
\hline $\mathrm{L} 2$ & - & Second language \\
\hline SDA & - & Second dialectal acquisition \\
\hline SLA & - & Second language acquisition \\
\hline TL & - & Target language \\
\hline UG & - & Universal Grammar \\
\hline
\end{tabular}

\section{Introduction}

\subsection{Background of the problem}

Before the introduction of the colonial era, people used to speak their own languages, which they termed as their mother tongue. Different communities had different languages depending on their origin, which resulted to a nation made of people speaking different languages. It is through the interaction of people from different communities and regions that resulted into individuals learning the other languages apart from their first language. This was seen as a good step since people could easily communicate with one another, although there were communication barriers that up to date are still experienced.

It is evident that the English language has become the second language of many people since the beginning of the mid-nineteenth century up to the current twentieth century (Joseph, 2003). According to Crystal (1987), declaration of the literacy carrier languages in the world is next to impossibility. This is attributed to the fact that, the world languages estimates lie in the range of five-to-ten thousand in total. The impact of literacy acquisition on any language has influence on economic, the social, existing demographic, and prevailing historical trends (Joseph, 2003).

In the current century, literacy acquisition mostly occurs in schools and other forms of social institutions. The institutions create adequate room for interaction of the members and facilitate the knowledge sharing process, as well as learning in the formal setting.. According to UNESCO (2009), English leads world languages as far as communication and publication is concerned. Crystal, (2012) observes that English has become the international language for business and commerce, science and technology and international relations and diplomacy with 1500 million speakers internationally. It is therefore important to learn English in order to fit in the global community 
In Kenya, the importance of English as a medium of instruction in schools goes back to the colonial period. According to Oluoch (2002), the Phelps Stoke Foundation in 1924 suggested that Kiswahili and other local languages be used as languages of instruction in schools. The same commission recommended that English be taught only in higher grades where teachers were capable of it. In 1925, the East Africa commission led by Hon. William George Arthur Ormsby - Gore M.P as chairman also recommended that local languages be used as a media of instruction at elementary stages. In secondary schools, English alone would be used as the medium of instruction, Great Britain \& Ormsby- Gore(1925).

According to sociolinguistics definition, the term dialect refers to varieties of the same language whose difference is on vocabularies, pronunciation and grammar, and is associated with a particular geographic region or social group (Ronald, 2010). The acquisition of a second language (henceforth L2) is greatly affected by age. According to Flege, Yeni-Komshian, and Liu, (1999), those who acquire the L2 after early childhood usually show different patterns of perceiving and production of L2 than the early learners, therefore, the late L2 learners are easily identified due to their D1 accent. This indicates that children who attend school at the age of five years and above are more likely to have problems in learning L2 as compared to those who attend school in their younger ages, less than five years. The second language learners in most cases have extraordinary problems in understanding the pronunciations and intonation patterns of their L2. According to (Ellis, 1985) second language theories indicate that second language learners are motivated by their various needs to achieve full mastery of the second language. It is also argued that Second language learners still access Universal Grammar but through their first language, with parameter values already set for that language. Therefore, some other factors in addition to UG, play a part in the learning of L2, for example, enough input and varying learning mechanisms.

According to Siegel (2010), SLA acquisition study aims at examining how people who speak L1 acquire an additional language (L2). On the other hand, the SDA study examines how people who already use D1 end up acquiring D2 of what their community are conscious of as to be the same language. To get the difference between dialect and language sometimes becomes difficult although the most used criterion is mutual intelligibility whereby the speakers of two differing dialects of the same language understand one another but the speakers of the two different languages cannot. However, this criterion is not a perfect method since it is dependent on some factors such as the attitude, beliefs and goodwill.

Learning of L2 is characterized by many varying factors that create different impacts on different language components that include syntax, semantics, phonology, and morphology that affect the nature and the time period for the L2 acquisition, (Birdsong, 1999). Evidence shows that many people, especially pupils in primary schools are greatly affected by their first language (henceforth L1) when it comes to speaking and writing of the English language (Njoroge, 2000).

According to (Rossi, Gugler, Hahne and Friederici, 2005), two factors, which are, the age of L2 acquisition (AoA) and the level of proficiency of the L2 use, determine the process of acquiring the L2 language. AoA indicates that the earlier the L2 is acquired the better and the faster a high level in L2 is attained. The way in which people speak a given foreign language is affected by their accent; therefore, it makes it difficult to clearly understand what an individual is saying, which creates a big problem for the language teachers. All these effects are because of the influence of different dialects from various communities that bring about the issue of accent (Hahne and Friederici, 2001).

In Kenya, most people from the rural areas face dialect problems in speaking English because they grow up in the villages where only one language is used, therefore face difficulties in acquiring the second or third languages. The person's ethno-linguistic heritage, which is the ethnic and speech of the community which the person is born into, plays a significant role in determining the degree of interaction and access to the language used by the dominant group therefore, creating a barrier to acquiring L2 (Gacheche, 2010). According to UNESCO (2009), many citizens from low-income countries work in the informal sectors that do not expose their children or adults to the dominant official languages thus making it difficult for these children to confidently use the language while at school.

\section{Literature Review}

\subsection{Second Language acquisition process}

According to Ellis (1994), study of a language, which learners give an output of in all their development stages, is the beginning point of L2 acquisition. The acquisition process identification occurs in several ways, which include the study of the learners' pragmatic features, errors portrayed, variability, and various types of development patterns. The errors identified are classified as developmental errors (errors associated with L1 acquisition), interference errors 
(errors reflecting mode of L1), and unique errors (errors that do not fall in either interference, or developmental categories).

According to Ellis (1994), L2 acquisition has a wide variety of meanings. It is viewed as any form of language that differs from the first language. L2 is often perceived as a foreign language. However, some learners may exhibit traits of multilingualism, whereby learners demonstrate competence in more than one L2. For effective study of L2, pragmatics needs adoption. This depicts that, a learner undertakes the learning process in circumstances that allow functioning and encoding of the language.

Muthwii and Kioko (2004) argue that, despite the fact that, public domain of Kenyan language has a historical background setting, a lot of language use has attributes to interaction of social setting, ethnicity factors, and developed attitude of citizens with regard to languages. There are three challenges that have faced language in education since the start of the colonial era. The first challenge is that language is to act as a medium of instruction. The second challenge concerns the level of education system at which the second language is introduced, and finally who the qualified teachers are, to teach the language. With the above in mind it is important to find out whether ethnicity or the region where one grows up in and the first language one uses in social circles has any positive or negative effect on learning English as a second language.

\subsection{Linguistic theories concerned with dialect in Learning English as a second language}

The acculturation model deals with factors associated with learners' resistance to adapt into a new culture of English language, which is the TL. The model recognizes the developmental nature of SLA and seeks to explain differences in learners' rate of development and the learners' level of achievement in terms of the extent that they adapt to the TL group. According to Schumann (1986), those who have limited communication in the target language seem to fossilize, while those with greater contact have more acquisition-taking place. Spolky (1989) criticizes Schumman's model arguing that it presupposes social factors to have a direct effect on SLA whereas they are more likely to have an indirect one. Schumann however, makes it clear that the amount of contact that the learner has with the speakers of the TL caters for the effect of the different social factors.

Selinker's 1972 Interlanguage theory approaches second language learning through a detailed analysis of the learners' own speech. Interlanguage dates back to the sixties when second language Acquisition was at its infancy. Interlanguage refers to the systematic linguistic behaviour of learners of second language and looks at the language of the learner as the interim grammar advancing towards the target language.

\subsection{Problems encountered by non-native speakers of English while learning English as a second language}

Majority of people encounter many problems when it comes to learning the second language experienced in both the written and spoken language. Over the past decade, the study of L2 speech emerged as a rapid growing area of great concern. The ramifications, which extend across a diverse range of disciplines, include Linguistics, psychology and education. Flege (1988) employed the phrase "speech learning" to refer to the processes by which a learner comes to perceive a speech sound differently after a big exposure to the foreign languages. L2 speech can be studied from a wide range of perspectives and therefore, many aspects of the L2 speech learning are explored in terms of phonological and phonetic factors tied to the similarities and differences between the sound system of L1 and L2. Along with the well-established findings that the older people mostly have problems in perceiving non-contrasts, investigators have been interested in how perceptual training can improve performance on various kinds of discrimination and identification tasks. The difficulties in perceiving a non-native perceptual contrast are characterized as a failure to attend to the phonetic cues that signal the distinction for proficient speakers of the L2.

Mother tongue dialect greatly affects most students in Kenya and brings about many problems in perceiving the L2 languages. Bartoo (2004) investigated on the acquisition of English syntax by Keiyo L1 speakers. In her study, she looked at the syntactic errors that result from L1 transfer in the process of acquiring English as a L2 by Keiyo speakers of English. She looked at the effects of the errors on the performance of the pupils, and whether teaching played a role in the eliminating the errors. She found out that, Keiyo L1 speakers made omissions, misordering, and misformation errors in the process of acquiring English. These errors, she says, inhibit the performance of learners. However, teaching plays an important role in the elimination of the errors.

According to Kioko and Muthwii (2000), the Kenyan learners have faced, and are still facing many challenges in acquiring the English language, with the problem revolving around the place and development of local indigenous languages. According to Philip Ochieng (Daily Nation, January 11, 2013), Bantu languages, conform to pronunciation. What this means is that, words are written the way we pronounce them. This presents problems when a Bantu speaker of a Bantu first language learns English because English is non-phonetic and spelling (orthography) 
violates pronunciation. In pronunciation, what we vocalize are vowels, and therefore to know the vocabulary of a language is to primarily, master of sounds. It is because English is a non-phonetic language that Bantu speakers of the language find it difficult to come to grips with the slight degree of difficulty (nuances) of its vowels. For example, for some people it could be difficult to bring out the difference in pronunciation between cat, cut \& cart. Njeru (2011) notes that Kiembu speakers (who are Bantu, Embu County, Kenya) have many phonological errors which in writing present in the manner in which they write words. She says this could be explained by the existing difference between English orthography and pronunciation. According to her, Kiembu graphic medium corresponds to pronunciation. This is not so in the English language.

On the other hand, most teachers in Kenya are not native English speakers which make them encounter many problems while teaching the language. Some of these challenges have serious effects on students learning the English language. First, non-native teachers of English have problems with pronunciation. The teacher makes incorrect pronunciation of English words and ends up transferring the phonological rules from their first language into their English speech. In addition, non natives teachers of English come up with their own pronunciations of English words borrowed from their first language (Melchers and Shaw, 2003).

Accent is the second problem with non native teachers of English while teaching the English language. Most often, non native teachers of English are fond of including their first language accent as they give English commands to their pupils. Teachers with strong L 1 accent, sometimes make it hard for listeners to clearly understand the words they are saying. On the other hand strong accent diminishes the understanding of some English words. The mother tongues of individual African speakers have a strong effect on their accent that produces different phonological characteristics in English pronunciation (Melchers and shaw, 2003; 155).

Grammar is the third problem faced by non native teachers of English in learning English language. English grammar is different from the grammar of the ethnic languages spoken in Kenya, and this makes most teachers have no understanding of how the English language really works. In addition, the first language fluency creates more problems in learning the English language. Teachers who are used to talk in a native language may lack the confidence to speak the English language and have a tendency of making mistakes. This tendency makes non native teachers of English afraid to talk the language to learners (Rosman, 2012).

Finally, lack of English language teachers with requisite skills is the beginning of most of the problems in English language teaching and learning. Most teachers teaching English at the primary school level do not know English well and consequently contribute to the perpetuation of English language errors among the learners. In such cases, the learners have no language model in class and yet this is crucial since imitation plays a significant role in language learning (Melchers and Shaw, 2003).

\subsection{The effects of a first language in learning the second language}

Corder (1967) observed that when people are learning a second language, they already have a first language. He also realized that the rules they have learned and understood in the first language are used in the second language. As a result, people form a habit of using the rules of the first language in the second language and therefore make errors. As such the effects of first language on learning second language are often experienced in both the written and spoken languages. These effects are related to pronunciation, spelling and grammar. Presently most educational systems are using mother tongue as the medium of language teaching especially in lower primary schools in the rural areas. There is an argument that pupils learn English more quickly and effectively by maintaining their proficiency in the mother tongue, (Butzkamm, 2003).

Pronunciation is a serious problem associated with learning the second language for both teachers and pupils. Pronunciation of English words is affected when pupils turn back to the villages and use their first language as a means of communication. On the other hand, teachers face difficult moments on establishing the systematic way of deciding what to teach, and how to do it. Lack of proper guidance on how to teach L2 makes teachers experience many difficulties in ensuring L1 learners pronounce certain English words correctly (Levis \& Levelle, 2012; 134).

\subsection{Training of teachers of English especially in primary schools}

The teacher, trained or untrained is that person who has willfully accepted the responsibility entrusted upon him by the nation to educate the young. The word teacher is defined as a person who, in the position of a leader or guide, attempts to shape or mould the behavior of another person through instruction and practical example, Mbiti (2007).

In Kenya, primary teacher training takes a period of two years. Out of these two years, nine weeks are dedicated to teaching practice. Teaching practice is the most important part of the professional training and hence should receive most attention. This is because a teacher cannot expect theory of teaching to see him through the classroom. 
Teaching practice is the time when the student teacher has his first chance to apply and try out methodology and principles that he has learnt theoretically at college. Effective organization of teaching practice program that takes into account all important aspects of teaching practice such as micro-teaching, demonstration, teaching and preparation of meaningful teaching aids should be designed carefully and strictly adhered to (Barasa, 2005).

Despite the fact that majority of Kenyans want to increase the quality of their children's English skills, lack of qualified teachers to teach English has been a problem in most primary schools. On the other hand, those teachers who get trained to teach in primary schools, their attainment in English language at form four is average. This means that their grasp of the language is not very impressive and they are likely to encounter problems while teaching the language (Barasa, 2005). To qualify for training as a primary school teacher, a candidate should have the following qualifications.

- $\quad$ Minimum grade C (plain) in KCSE and a minimum grade of D (plain) in Mathematics and C- (minus) in English

- In 2012, the Government of Kenya came up with a policy framework for Education: Aligning Education and Training to the Constitution of Kenya (2010) and Kenya Vision 2030 and Beyond. In this policy paper, teacher primary education is set to change. Qualifications for training will be higher where those aspiring to become teachers of English must attain $\mathrm{C}+$ and above and will train for a Diploma in Education. The training will take 3 years. Previously, trainees would have a C- in English and would train for 2 years for a certificate course. The government aims at improving the proficiency of teachers by giving them a higher training and therefore making them better. Hopefully this will make them better teachers of English.

\section{References}

Barasa, P. L. (2005). English language teaching in Kenya: policy, training and practice. Eldoret, Kenya: Moi University Press.

Bartoo, J. P. (2004). Acquisition of English Syntax by Keiyo L.I speakers. Unpublished Thesis, Egerton University.

Birdsong, D. (1999). Second language acquisition and the critical period hypothesis. linguistic Society of America.

Brown, D. (1994). Principles of Second Language Teaching and Learning. $3^{\text {rd }}$ ed. Englewood cliffs, New Jersey: Prentice Hall.

Butzkamm, W., (2003). We only learn language once: The role of the mother tongue in EFL classrooms, death of a Dogma, Language Learning Journal, 31.

Corder, S.P. (1967). The Elicitation of Interlanguage. New York: Oxford University Press.

Crystal, D. (2012). English as a Global Language, Cambridge University Press.

Crystal. D. (1987). The Cambridge Encyclopedia of Language. Cambridgeshire Cambridge university press.

Ellis, R. (1985). Understanding second language acquisition, Oxford University press.

Ellis, R. (1994). The Study of Second Language Acquisition. The $10^{\text {th }}$ Edition. Oxford University.

Flege, J. E. (1988). Factors affecting degree of perceived foreign accent in English sentences. Journal of the Acoustical Society of America, 84(1), 70-79.journal of the Acoustical Society of America. http://dx.doi.org/10.1121/1.396876

Flege, J. E., Yeni-Komshian, G. H., \& Liu, S. (1999). Age constraints on second-Oxford University.

Gacheche, K. (2010). Challenges in Implementing a mother tongue-based language-In education policy: Policy and practice in Kenya. University of Leeds. POLIS Journal Vol. 4.

Great Britain, \& Ormsby-Gore, W.G.A. (1925). East Africa: Report of East Africa Commission. London: H.M. Stationary off.

Hahne, A., \& Friederici, A. D. (2001). Processing a second language: Late learners' comprehension mechanisms as revealed by event-related brain potentials. Bilingualism: Language and Cognition, 4, 123-141. http://dx.doi.org/10.1017/S1366728901000232

Joseph, B. (2003). When Languages Collide: Perspectives on Languages Conflict. Columbus: The Ohio State University Press.

Kioko, N. A and Muthwii, J. M. (2000). The Demand of a Changing society: English in Education in Kenya Today. Department of English and Linguistics: Kenyatta University. 
Levis, John \& Kimberly Le Velle. (2012). "Social factors in pronunciation acquisition”. Pronunciation for second language learning \& teaching. Lowa State University.

Mbiti, D. M, (2007). Foundations of school Administration. Nairobi: Oxford University press.

Melchers, gunnel \& Shaw, Philip. (2003). World Englishes. London: Hodder Education. Print.

Multilingual Matters and new challenges. Language and Speech, 46, pp. 87-113kingston Press Ltd.

Muthwii, M \& Kioko, A. (2004). New Language Bearings in Africa: A Fresh Quest.

Njeru, M. G. (2011). Errors in the written English of primary school pupils in Nembure Division, Embu West, Kenya. Unpublished Thesis Chuka University College.

Njoroge, C. (2000). Factors affecting availability, acquisitions and utilization of resources in the teaching of English in selected Kernyan secondary schools, Kenyatta University.

Ochieng, P. (2013, January 11). When Kiswahili adopts certain English words. Daily Nation. [Online] Available: http://www.nation.co.ke/oped/Opinion/When-Kiswahili-adopts-certain-English-words/-/440808/1663362/-/o2w utt/-/index.html

Oluoch, G. P. (2002). Essentials of Curriculum Development. Nairobi: Bird Printers.

Ronald W. (2010). An Introduction to Sociolinguistics. (6 ${ }^{\text {th }}$ Ed.). U.K: John Wiley \& Sons, Ltd; 23.

Rosman Norhidayu. (2012). Problems faced by Non-Native English speakers. [Online] Available: http://www.slideshare.net/NorrhidayuRosman/problems-faced-by-nonnative-english-speakers.

Rossi, S., Gugler, M. F., Hahne, A., \& Friederici, A. D. (2005). When word category information encounters morphosyntax: An ERP study. Neuroscience Letters, pp. 228-233. http://dx.doi.org/10.1016/j.neulet.2005.04.077

Schumann, J. (1986). Research on the Acculturation Model for Second Language Acquisition. Journal of Multilingual Development P. 379-392. http://dx.doi.org/10.1080/01434632.1986.9994254

Selinker, L. (1972). Rediscovery Interlanguage London: Longman.

Siegel, J. (2010). Second Dialect Acquisition. united Kingdom: University Press. http://dx.doi.org/10.1017/CBO9780511777820

Spolsky, B. (1989). Conditions for Second Language Learning. Oxford: Erlbaum Associates Publishers, New Jersey.

UNESCO (2009). Advocacy Brief on Mother Tongue-based Teaching and Education for Girls. Bangkok: UNESCO. 